\title{
¿POR QUÉ LA PROPENSIÓN A APRENDER SE INHIBE EN LOS NIÑOS Y LAS NIÑAS EN LA ESCUELA?
}

Why children's propensity to learn is inhibited in school?

¿Por que há inibição da propensão a aprender quando os meninos e meninas estão na escola?

\section{Silvia López de Maturana Luna}

Universidad de La Serena, Chile. Fono: +56 512 204478. Correo electrónico: silvialml@ gmail.com

\section{Resumen}

El aprendizaje connatural a todos los niños y las niñas se va transformando en la escuela en una tarea ardua, dificultosa y aburrida, y el deseo y placer por aprender da paso a la obligatoriedad y al sentimiento de incapacidad. Ellos/as no son conscientes de la gran riqueza epistemológica de sus saberes pero quiénes les educan deben saber de qué son capaces, por qué lo son y hasta dónde podrían llegar si son guiados/as adecuadamente. Todos/as propenden a aprender pero esta capacidad se pierde no por la maduración biológica, psicológica, social y cultural, sino por la influencia negativa de un modelo paradigmático de concebir el aprendizaje. Quiénes trabajamos en la escuela, estamos en condiciones de mostrar que los niños y las niñas son geniales, que no hay que luchar contra ellos para que aprendan, sino ayudarles para que fluyan como aprendientes gozosos. No es una perspectiva utópica, ya que somos profesionales que nos hemos preparado para tales menesteres.

Palabras clave: Propensión a aprender, Mediación, Ambientes activo modificantes.

\begin{abstract}
All children's innate learning is transformed into a tough, difficult and tedious task in school, and the desire and pleasure in learning leads to the obligation and the feeling of personal inadequacy. They are unaware of the great epistemological wealth of their knowledge but those who educate them must know what they are capable of, why they are and how far they could get if they are led properly. All of them tend to learn but this ability is lost not because of biological, psychological, social and cultural maturation, but by the negative influence of a paradigmatic model of thinking about learning. We who work in the
\end{abstract}


school we are able to show that children are great, we must not fight them to learn, but to help them to flow as joyful learners. It is not an utopian perspective because we are well prepared professionals for such duties.

Keywords: Propensity to learn, Mediation, Active modifiers environments.

\section{Resumo}

A aprendizagem connatural a todos os meninos e meninas vai se transformando, na escola, em uma tarefa árdua, difícil e desmotivadora, assim como o desejo e o prazer por aprender cedem lugar à obrigatoriedade e ao sentimento de incapacidade. Eles e elas não tem consciência da grande riqueza epistemológica de seus saberes, mas quem os educa deve saber do que são capazes, porque o são e até onde poderão chegar se guiados adequadamente. Todos e todas são propensos a aprender, mas esta capacidade se perde não pela maturação biológica, psicológica, social e cultural, mas sim pela influência negativa de um modelo paradigmático de conceber a aprendizagem. Nós, que trabalhamos na escola, estamos em condições de mostrar que as crianças são geniais, que não é necessário lutarmos contra elas para que aprendam, ao contrário, precisamos ajudá-las a seguir o fluxo de uma aprendizagem significativa e feliz. Essa não é uma perspectiva utópica, pois somos profissionais formados para tais exigências.

Palavras-chave: Propensão a aprender, Mediação, Ambientes ativo modificantes.

\section{¿POR QUÉ LA PROPENSIÓN A APRENDER SE INHIBE EN LOS NIÑOS Y LAS NIÑAS EN LA ESCUELA?}

¿Qué hijos vamos a dejarle al mundo? (Meirieu, 2010)

Las observaciones permanentes en jardines infantiles y en escuelas, las publicaciones sobre aprendizaje infantil y las investigaciones realizadas y revisadas, nos evidencian que los niños y las niñas no aprenden en la escuela, y cuando creen hacerlo solo muestran un acto mecánico conducente al deterioro del pensamiento y de la autoestima que, muchas veces, termina en el fracaso escolar que excluye, rotula y denigra. El aprendizaje connatural a todo ser humano se va transformando en una tarea ardua, dificultosa y aburrida, y el deseo y placer por aprender da paso a la obligatoriedad y al sentimiento de incapacidad. En estos casos se observa la gran paradoja humana, que consiste en que tenemos un cerebro con 
infinitas posibilidades de aprendizaje, y elegimos, quizá sin darnos cuenta, inhibirlas y deteriorarlas.

Cada vez que observamos a los párvulos en sus experiencias cotidianas en los jardines infantiles, nos han fascinado sus preguntas y respuestas, producto de la propensión a aprender que se pierde no por la maduración biológica, psicológica, social y cultural, sino por la influencia negativa de un modelo paradigmático de concebir el aprendizaje.

En consecuencia, los desafíos que plantea la educación escolar se refieren a los modelos que sustentan y orientan el trabajo pedagógico y a las diversas circunstancias que contextualizan y construyen el sentido educativo, razón por la cual siempre es un riesgo suponer que las limitaciones epistemológicas que fundamentan el modelo vigente de escolaridad, se superarán solo con buenas intenciones o declaración de principios. Las reformas educativas intentan preocuparse del problema pero se sigue manteniendo y reforzando un sistema escolar basado en la repetición y no en la creación.

Uno de los grandes desafíos de las instituciones educativas escolares es optimizar el proceso de formación integral de los niños, niñas y jóvenes, donde el profesorado es quien media, guía y facilita la creación de ambientes activos modificantes para que eso suceda. Desde los primeros años de escolaridad, el rol mediador consiste en facilitar y no entorpecer el aprendizaje; proponer y no imponer ideas propias; corregir y no sancionar los errores; estar presente o alejarse si su presencia inhibe al niño o a la niña; respetar el ser, pero sugerir modificar el hacer del alumnado. Para el profesorado mediador, la equivocación y la verdad no constituyen polos antinómicos, sino aspectos de un proceso sin fin, donde no importa tanto si el niño o la niña está equivocado/a o si tiene razón, sino que, lo que realmente importa, es que debe comprender por qué está equivocado/a o por qué tiene razón. No es la respuesta lo principal, sino la comprensión que tenga del proceso.

La educación es una experiencia social en la que los diferentes actores que intervienen en la formación de los niños y de las niñas se interrelacionan para que ésta sea integral, sistémica y holística. Lamentablemente, desde la más temprana edad, los y las niños/as se escolarizan y las intenciones educativas no trascienden del mero discurso. En este contexto, entendemos a la escolarización como la repetición de relaciones preestablecidas y a la educación como la creación de relaciones posibles (Calvo, 2013). 
La escolarización atrapa al niño y a la niña apenas cruza el umbral de la escuela y exige el cumplimiento a la excelencia que ha sido decidida por un poder instituido que construye la 'relación pedagógica asimétrica' de la escuela (Perrenaud, 1990), donde no todos tienen las mismas posibilidades ni oportunidades. El curriculum parece confeccionado para un tipo ideal de niño y de niña, en el que no todos encajan. De esa manera, el objetivo pragmático de la escuela no resta distancia al plano axiológico que se manifiesta en el poder que decide lo que hay que aprender y para qué hay que aprenderlo. La superación de la brecha está en el desarrollo de las habilidades del pensamiento y en la conciencia de que se poseen y utilizan adecuadamente.

Revisando la investigación del Fondo Nacional de Investigación Científica y Tecnológica, Fondecyt No 1110577/2011-2015: 'Asombros educativos infantiles y propensión a aprender', donde se hizo seguimiento a niños y niñas desde los cuatro años hasta que cumplieron los siete años de edad, encontramos suficiente evidencia empírica para asegurar que la enorme potencialidad que muestran en los primeros años de educación formal (pre escolar) se va anquilosando rápidamente durante los procesos escolarizantes de la escuela. Por ejemplo:

Las respuestas de los niños y de las niñas nos permiten afirmar que se trata de aprendizajes hechos sin esfuerzo ni aburrimiento, sino que fluyen de manera activa y entusiasta como parte de su existir. Cuando se sienten sobrepasados simplemente dejan de lado la tarea y la postergan. Lo mismo sucede con sus argumentaciones, que no son el resultado del razonamiento lineal, sino que son la expresión de inferencias intuitivas y extraordinarias formuladas de manera directa y sin retórica. Simplemente preguntan por qué quieren aprender. Asumimos que esa simplicidad esconde una tremenda complejidad que da cuenta de la capacidad de aprendizaje que poseen y que no depende de una secuenciación ordenada y lineal como pretende la escuela. A saber:

Álvaro y un compañero ( $\left.1^{\mathrm{a}} \mathrm{EGB}\right)$ miran por la ventana.

Compañero: “¡Oye mira los pájaros!” apunta unas aves en el techo del edificio del frente.

Álvaro: “¡No son pájaros!”

El compañero mira a Álvaro con confusión.

Álvaro: “iMira po, son tres gaviotas y dos palomas!” 
El compañero mira detenidamente y exclama: “¡Aaah!”

Álvaro: “¿Oye, sabí en qué se parecen las gaviotas a los dinosaurios?”

Compañero: “№ sé!”

Álvaro apuntando hacia las gaviotas: “¡En las patas po, mírale las patas a las gaviotas y acuérdate cómo son las de los dinosaurios, iguales po!”

La profesora los mira, se acerca rápidamente y les dice: “¡A ver, están mirando por la ventana, si les gusta tanto se van para afuera!"

Este comentario infantil nos sorprende por lo simple y lo complejo, a la vez, que se esconde detrás de sus palabras y nos preocupa la llamada de atención de la profesora. Qué pérdida para el desarrollo de la propensión a aprender de Álvaro si ese comentario, como tantos otros, se deja pasar sin mediarlo, sin continuar conversando, no para dar respuestas sino para instigar la emergencia de otras preguntas o la propia respuesta del niño. Ese comentario infantil contiene conocimiento, reflexión y una serie de funciones cognitivas que forman parte de su acto mental, compuesto por las fases de entrada, elaboración y salida de la información. Cada una con una serie de funciones cognitivas, interrelacionadas pero interdependientes, que favorecen o entorpecen el proceso de aprendizaje (Feuerstein, 1991).

Si hacemos un análisis del acto mental que puso en acción Álvaro al hacer las preguntas y comentarios sobre las gaviotas y los dinosaurios, podemos señalar que se observan las siguientes funciones cognitivas en cada una de las fases respectivamente. En la fase de entrada de la información: la exploración sistemática de una situación de aprendizaje, las habilidades lingüísticas y la percepción clara. En la fase de elaboración: la conducta comparativa, la evidencia lógica, la distinción de datos relevantes y el razonamiento hipotético. Y en la fase de salida de la información: la proyección de relaciones virtuales, la desinhibición de la respuesta, las habilidades lingüísticas y la precisión y exactitud para dar la respuesta.

Evidentemente, el niño no es consciente de la gran riqueza epistemológica de su comentario; pero quiénes lo educan deben saber de qué es capaz, por qué lo es y hasta dónde podría llegar si es guiado adecuadamente. Tememos que la capacidad de Álvaro sea desvalorada, pues la enseñanza y el aprendizaje formal que exige repetición, no valora el 
aprendizaje informal que exige emergencia y divergencia. Uno es lógico, lineal, secuencial y coherente. El otro es caótico, emergente, ambiguo y contradictorio. Sin embargo, esto no significa que el segundo sea incoherente, ilógico o desordenado, solo que obedece a lógicas diferentes que explican los procesos de aprendizaje.

¿Qué relaciona Álvaro cuando compara las patas de las gaviotas con las patas de los dinosaurios?; ¿Comprenderá que aquello es una operación mental de alto nivel?; ¿Qué aprenderíamos si pudiéramos conocer y analizar toda la información que este niño posee y maneja, la mayor parte inconsciente, cuando establece ese tipo de relaciones?; ¿Qué nos enseñaría respecto a cómo conoce, elabora y comunica esos saberes aprendidos informal y caóticamente? Las respuestas a estos interrogantes son cruciales para los que trabajamos con estudiantes, pues podríamos estar en condiciones de mostrar que los niños y las niñas son geniales, que no hay que luchar contra ellos para que aprendan, sino ayudarles para que fluyan como aprendientes gozosos.

Las preguntas y respuestas infantiles son de una complejidad asombrosa que difícilmente encontramos en los escolares de cursos superiores. Eso nos lleva a preguntarnos qué ha pasado con la propensión a aprender, y la respuesta que aflora es que la escuela incuba condiciones favorables para frenarla, por ejemplo, fragmenta los saberes en parcelas súper especializadas sin relación entre ellos ni con la experiencia cotidiana. Sin embargo, el aprendizaje infantil informal es holístico, razón por la cual el niño y la niña no separa en partes aisladas lo que aprende, sino que conforma totalidades sinérgicas con mayor o menor coherencia. Este aprendizaje es cualitativamente diferente al de la escuela que fuerza una enseñanza lineal y dicotómica perturbadora de la propensión a aprender de los niños y las niñas y que es dependiente del paradigma científico vigente, por lo que no es fácil cambiarlo. Los más afectados son los niños y las niñas de sectores socioculturalmente más deprivados ya que están más desprovistos de la guía intencionada de un mediador o mediadora que facilite su aprendizaje desde los primeros años de educación formal.

En la mayoría de los jardines infantiles y de las escuelas existe un tipo de ambiente pasivo aceptante, homogéneo, estructurado y parcelado, con una programación rígida que limita e inhibe las experiencias de éxito de los niños y de las niñas, restringe la creatividad, el ingenio, la reflexión, la entretención y el sentimiento de ser competente. Existe 
invisibilidad de la complejidad infantil porque se refuerza la percepción episódica de la realidad, no se aprovechan los errores, hay poca intencionalidad y significado, las experiencias son muy guiadas y lineales y las habilidades lingüísticas son poco aprovechadas, ya que se restringe la posibilidad de diálogo y de construcción de aprendizajes (Moreno y López de Maturana, 2015).

Ahora bien, dado que los niños y niñas no crecen en el vacío socio cultural, consideramos que el medio puede potenciar o inhibir su desarrollo cognitivo. Entendemos que el medio lo constituyen los ambientes socioculturales donde el niño y la niña vive sus experiencias cotidianas, las que contribuirán, en mayor o menor medida, al aprovechamiento de los aprendizajes. Si los ambientes son activo modificantes hay mayor posibilidad de actualizar el desarrollo y viceversa. Sin embargo, un niño que en su hogar no cuenta con un ambiente adecuado, puede modificarse cognitivamente en la escuela, siempre que se den las condiciones para hacerlo. Es fácil suponer qué le espera a los niños que no han sido mediados ni en el hogar ni en la escuela (Moreno y López de Maturana, 2015).

Para favorecer el ambiente activo modificante en la escuela, el profesorado mediador debe ayudar a generar preguntas para favorecer la toma de conciencia y el desarrollo de las funciones cognitivas, descritas por Feuerstein (1991) como los pre requisitos del pensamiento inteligente. Incluso, para dar un paso más allá en la concienciación. A saber, los niños y las niñas tienen que preguntarse: ¿qué hago para reunir los datos?; ¿qué hago para procesarlos?; ¿qué hago para comunicar con éxito lo que aprendí? Cuando logren contestar a esas preguntas -que también debe hacérselas el profesorado- habrán incrementado la capacidad de aprender, utilizar lo aprendido y aplicar a otros contextos.

Las implicancias educativas que el desarrollo de las funciones cognitivas tiene en la escuela es innegable. El niño y la niña tiene que aportar con sus conocimientos y sus aplicaciones, ser capaz de tomar decisiones acertadas, solucionar problemas, relacionar distintas situaciones, emitir juicios, hacer conjeturas, etc. Un niño o una niña con funciones cognitivas deficientes no comprende lo que lee ni lo que escribe a pesar que ante los estímulos, elige de lo que ve lo que le sirve o lo que le gusta; lo que lo atrae y lo que rechaza. Selecciona la naturaleza de las respuestas y queda afectado/a por la naturaleza de 
su desarrollo. La acumulación de datos que a diario se desparraman sobre él o ella, le dificultan discernir entre lo relevante y lo irrelevante y, por ende, transformar los datos en información.

Si los niños y las niñas tienen funciones cognitivas deficientes en la fase de entrada, reciben mal la información, por lo que aunque la elaboren de acuerdo a criterios lógicos rigurosos, entregan una información incorrecta. Ahora bien, si la información recibida es correcta pero mal elaborada, lo más probable es que la respuesta dependa del azar, disminuyendo la seguridad en sus procesos mentales. Por último, se da el caso de aquellos niños o niñas, que reciben y procesan bien la información, pero carecen de las herramientas para entregarla, por lo que fracasan en su intento. No saben como decir lo que saben. Evidentemente, esto redunda en la autopercepción que es fundamental para el desarrollo de la autoestima.

Generalmente en la escuela, la falta de instrumentos verbales tanto de la fase de entrada como de salida de la información es una de las causas más significativas de fracaso. Lo mismo pasa con la constancia y permanencia del objeto puesto que si no se puede apreciar lo que permanece, menos se podrá apreciar lo que cambia, y el niño o la niña se verá seriamente obstaculizado/a para profundizar hacia niveles de mayor complejidad y abstracción. Este aspecto es de medular importancia en el proceso educativo del sistema escolar.

No vemos diferencias entre niños y niñas de sectores populares, mal llamados vulnerables (los/as consideramos vulnerados/as), con los hijos de profesionales y de buen pasar económico y cultural más refinado. Señalamos que las diferencias son culturales, es decir, aprendidas, a posteriori, y, por lo mismo, evitables o reversibles, e inferimos que la formalidad escolar no incentiva los ambientes activo modificantes y no valora los ambientes informales pues, por su mismo carácter de informalidad, le hemos atribuido falta de certezas y los hemos caracterizado por bajísimas expectativas, excesivo control, constantes retos y participación artificial. Todo lo contrario de lo que es inherente al deseo de aprender en la infancia.

El peligro estriba en que se asume de manera tácita que 'de esa forma' se enseña en la escuela, razón por la cual se requiere de un despertar de la conciencia para no 
entramparnos en la imagen de mundo preestablecido que nos mantiene en un ambiente pasivo aceptante. Es la 'falsa conciencia' (Romano, 1998) la que entrampa de tal manera al pensamiento que no le permite funcionar de manera autónoma. Se acepta dócilmente todo lo que se ve, se lee y se escucha. No hay disenso ni conciencia crítica que emane de la opinión autónoma. Como la sumisión y la pasividad cognitiva otorgan seguridad, no hay conciencia, por lo que se cree que tampoco hay consecuencias. Bajo esta óptica, es fácil comprender por qué no se le da credibilidad a los niños y a las niñas que muestran capacidades diferentes, por ejemplo a los más lentos, ya que de antemano se los ha predestinado al fracaso. La escuela tiene que reconocer la diferencia y no discriminar entre los que saben y los que no saben.

Los niños y las niñas llegan a la escuela con preguntas y deseos de aprender y el sistema les ofrece más certezas que incertidumbres. No es extraño entonces, que desde el primer año de escuela, sientan temor no solo de preguntar, sino también de responder. Recurrirán a las frases estereotipadas y aprendidas de memoria y no tendrán conciencia del proceso que les lleva a dar tal o cual respuesta, ni se preguntarán por lo que están conociendo. Recordemos a la profesora de Álvaro, quien ante el sorprendente comentario del parecido de las patas de las gaviotas y de los dinosaurios dice: “زA ver, están mirando por la ventana, si les gusta tanto se van para afuera!"

La pregunta ayuda a que el conocimiento forme parte de la estructura del pensamiento de los niños y de las niñas y evita el mecanicismo que una vez utilizado se olvida. El temor a hacer preguntas es resultado de la domesticación, nos advierte Romano (1998). Las pautas que configuran la cultura escolar no consideran a la pregunta como base del entendimiento y tanto alumnado como profesorado aprenden a no hacer preguntas en la escuela, incluso actualmente en que los medios tecnológicos de información entregan un terreno fértil para la indagación y la re-creación. Sin embargo, reaccionan de manera distinta fuera de la escuela donde las preguntas extra muros escolares surgen rápidas y fluidas. Por eso, un buen recurso para los educadores son los patrones de la vida cotidiana de los niños y de las niñas. Esta potencialidad dialógica y cultural es un avance cualitativo respecto a los métodos de educación tradicional y una buena forma de participación en la escuela que posibilita el acceso al conocimiento y a la motivación de logro. 
La pregunta favorece la relación dialógica y acorta la distancia entre el profesorado y el alumnado. El rol del educador/a mediador/a es adecuar su práctica para que los niños y las niñas sean partícipes activos del proceso de aprendizaje. De acuerdo a Feuerstein (1991), se trata de encontrar el índice de capacidad para aprender que existe en el niño y en la niña y que muchas veces está oculto. El mismo autor piensa que cuando un niño o una niña tiene un bajo rendimiento, la causa está en el mal uso de los factores

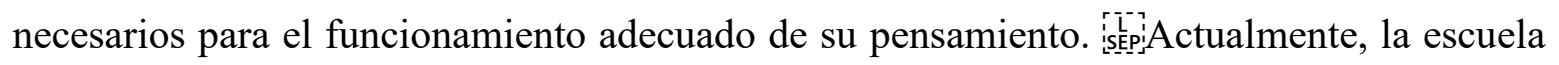
tiene grandes posibilidades de generar ambientes activos modificantes gracias a las nuevas tecnologías, ya que mientras más fuerza tiene el medio, más activo es el receptor. Paradójicamente en la escuela, la fuerza del medio disminuye y la pasividad atrapa al receptor.

El profesorado mediador tiene que sentirse partícipe activo y no solo mero reproductor, ya que son los que llevan las reformas al aula. Hay que valorar la cotidianeidad y conectarla al curriculum escolar para articular eficientemente el conocimiento. Eso implica investigar permanentemente sobre el aprendizaje de los niños y de las niñas y sobre la enseñanza del profesorado. Por un lado cabe preguntarnos: ¿cómo piensa este niño o esta niña?; ¿cómo construye el conocimiento?; ¿qué puedo hacer para enseñarle lo que realmente necesita?; ¿qué es lo más relevante para él y para ella?; ¿qué hacer para que aprenda mejor?; ¿en qué habré influido para que no aprenda?, etc. Y por otro lado, preguntarnos: ¿quién o quiénes seleccionan el conocimiento?; ¿quién o quiénes lo organizan?; ¿quiénes realmente se benefician de dicho conocimiento?; ¿por qué se indica que se enseñe de este modo y no de otro?; ¿cuáles son las intenciones de los que norman el curriculum?,;¿qué tengo que decir en relación a esto?, etc.

Estas preguntas, con más frecuencia de lo que uno quisiera, no aparecen en el repertorio mental del profesorado, puesto que la mayoría de las veces las normativas superiores se reciben con pasivo beneplácito. iَsêpise requiere adoptar una postura crítica y compartir con Freire (1990) su preocupación ante los actos del conocimiento, quien también se pregunta: ¿Cuáles son nuestras concepciones en la teoría del conocimiento?; ¿Cómo abordamos el objeto de conocimiento?; ¿Lo poseemos?; ¿Lo llevamos en el portafolio para distribuirlo entre nuestros estudiantes?; ¿Utilizamos este objeto de conocimiento para alimentar a los estudiantes o para estimularlos a conocer?; ¿Los 
estimulamos a asumir el rol de sujetos o el de receptores pasivos de nuestro conocimiento?

Evidentemente, no basta solo con formularlas, sino que se necesita tomar conciencia de ellas para precisar las intenciones educativas y las guías de acción adecuadas que hagan del proceso educativo una verdadera instancia de aprendizaje dialógico que permita vincular el poder y el conocimiento puesto a disposición (y el no puesto a

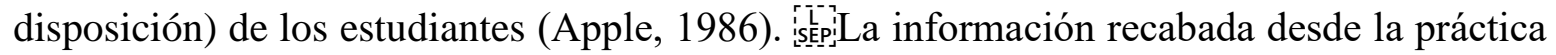
pedagógica debe ser coherente con los principios que la sustentan, así se conforma la comprensión y las bases teóricas fundamentadas en función a esta práctica, y cuya comprensión cabal favorece la puesta en marcha de innovaciones curriculares pertinentes. Una vez que los fundamentos epistemológicos del proceso intenten dar respuestas a éstas y otras interrogantes, se podrá obtener información relevante sobre qué, cómo, para qué, por qué, a quiénes, dónde enseñar y cómo encauzar el aprendizaje a través de una enseñanza que influya positiva y verdaderamente en el desarrollo de cada uno de los niños y de las niñas.

Es indispensable una transformación radical de las formas de enseñar para actualizar la propensión a aprender de los niños y las niñas, lo que implica consecuencias epistemológicas trascendentes para la escuela. En este contexto, el nivel de educación parvularia, dado los principios que lo rigen, favorece las instancias de modificabilidad emocional y cognitiva. Sin embargo, en ocasiones, se desaprovechan, originándose burocracia a niveles de aula, sin cambio en las prácticas pedagógicas rutinarias y cómodas que favorecen un tipo pasivo de planificación, ejecución y evaluación. Este nivel aún no se escolariza ante un sistema que aturde las funciones cognitivas ni asume las pautas escolares que enseñan a estar quietos, a no mirar para el lado, a no comentar ni compartir con el/la compañero/a del lado; a obedecer al pie de la letra y solo responder lo que se quiere que se responda, etc.

Por cierto, es difícil cambiar la práctica aprendida sin un análisis profundo y comprometido del significado de las concepciones que están implícitas en ella, como también sobre la naturaleza de las fortalezas y debilidades que van emergiendo cotidianamente, o cuando ni siquiera se piensa en por qué las prácticas pedagógicas se realizan de una forma específica y no de otra. Al no haber conciencia de la reproducción 
del círculo vicioso de la escolarización, se sobrestima el curriculum tradicional sobre cualquier alternativa curricular. Se subordina a una conciencia hegemónica que no discute ni cuestiona y acepta apaciblemente los criterios foráneos.

El cambio es percibido como una amenaza puesto que para el sistema oficial la heterogeneidad implica menos posibilidad de control; y para el profesorado lo es el temor a la sanción por desobedecer la normativa. Esto genera mecanismos de defensa que amenazan el orden y el control. Puede que se intente el cambio, pero en poco tiempo se vuelve a las prácticas antiguas evitando la reflexión sobre los propios procesos y la acción sobre la práctica. El gran temor de los profesores para atreverse a dejar las viejas costumbres, es que no saben qué hacer ante los cambios y prefieren seguir viviendo en la 'acumulación de niebla y humo' (Ferguson, 1991) que los protege de la realidad amenazante.

La enseñanza escolar requiere una visión optimista ante las dificultades de los niños y de las niñas, sobre todo, ante los determinantes distales que tradicionalmente son considerados causa del fracaso escolar: problemas socioculturales, emocionales, ambientales, genéticos, económicos, etc. La mediación como enfoque activo modificante, posibilita visualizar una salida para las situaciones en que la realidad escolar se torna dramática en cuanto a los resultados que se obtienen desde el comienzo de la escolaridad y no cesan hasta los grados superiores. La Experiencia de Aprendizaje Mediado (Feuerstein, 1991) es una buena oportunidad de incentivar al profesorado y al alumnado hacia la recuperación del gusto por aprender. La mediación es un determinante proximal para el logro del desarrollo del pensamiento autónomo y favorece que el niño y la niña sepan utilizar lo aprendido. Quien media, al conocer el poder de la interacción cualitativa, puede saber lo que quiere o necesita el niño o la niña y aplicar estrategias de interacción específicas y pertinentes.

Hay que generar estrategias sinérgicas, no invasivas, que transformen a los jardines infantiles y a las escuelas en ambientes activos modificantes donde germinen y fructifiquen relaciones multidireccionales entre los y las que educan y quiénes son educados que, por cierto, se influyen mutuamente. El ambiente pasivo aceptante inhibe y anquilosa las habilidades del pensamiento, pavimentando el camino de la rutina y la 
enajenación (López de Maturana, 2015).

La cultura escolar tiene que recuperarse de la enfermedad 'paidogénica' (Ferguson, 1991), provocada por el mismo sistema educativo que la ha tenido postrada por tanto tiempo, para que pueda aliarse y complementarse a los nuevos cambios. Los niños y las niñas son los que mañana tomarán el relevo de las generaciones adultas, por lo que es necesario que el progreso del conocimiento sea un instrumento de promoción y no de discriminación del género humano (Delors, 1996). Si la escuela continúa excluyendo a los niños que necesitan mediación, será difícil que actualicen sus potencialidades y salgan del círculo vicioso de la rutina escolar.

A pesar de que la infancia ha encontrado un lugar de reconocimiento social y los niños y las niñas han superado muchas de las carencias de antaño, en la educación, salud, legalidad, etc, ello no significa que el problema de la infancia esté superado, porque el riesgo de la pobreza no solo es material, puesto que tiene que ver con la participación efectiva en la vida social, y eso requiere de experiencias educativas significativas y trascendentes para que no que sientan limitados ni desconfiados de sus propias capacidades (Gaitán, 2010).

Las instituciones educativas escolares y la familia se enfrentan a un nuevo desafío en la sociedad actual tan incierta y cambiante, donde ocurren procesos de socialización muy distintos a los que existía en sus propias infancias. Hoy en día los niños y las niñas tienen que aprender a vivir experiencias en un campo de incertidumbres con efectos impredecibles a los cuales deben ajustarse continuamente. Necesitan un gran desarrollo de sus habilidades para integrar las diversas experiencias en un todo coherente, para comunicarse, autocontrolarse, tomar iniciativas y tener confianza en si mismo (Gaitán, 2010).

Mejorar la calidad de la educación tiene que dejar de ser un repetido y estereotipado discurso. Los educadores y las educadoras, los profesores y las profesoras, tenemos que creer que todos los niños y las niñas están en condiciones de aprender, y no solo quiénes aparentemente tienen desarrollada la capacidad. No es una perspectiva utópica, ya que somos profesionales que nos hemos preparado para tales menesteres.

\section{Referencias Bibliográficas:}

Apple, M. (1986). Ideología y Currículo. Madrid: Ediciones Akal. 
Calvo, C. (2013). Del mapa escolar al territorio educativo. La Serena: Editorial Universidad de La Serena.

Delors, J. (1996). La Educación Encierra un Tesoro. Compendio: Informe a la UNESCO de la Comisión Internacional sobre la Educación para el Siglo XXI. Ediciones UNESCO.

Ferguson, M. (1991). La Conspiración de Acuario. Transformaciones personales y sociales en este fin de siglo. Buenos Aires: Troquel.

Feuerstein, R. (1991). Mediated Learning Experience (MLE). Theoretical, Psychosocial and Learning implications. London: Freund Publishing House Ltd.

FONDECYT (2001-2015) No 1110577. Fondo Nacional de Investigación Científica y Tecnológica. Asombros educativos infantiles y propensión a aprender. Santiago de Chile. CONICYT.

Freire, P. (1990). La naturaleza política de la Educación. Barcelona: Paidós.

Gaitán, L. (2010). Ser niño en el siglo XXI. Cuadernos de Pedagogía, 407 monográfico. No identificador: 407.001. España.

López de Maturana, S. (2015) Maestros en el Territorio. $2^{a}$ edición. La Serena: Editorial Universidad de La Serena.

Meirieu, P. (2010). Una llamada de atención. Carta a los mayores sobre los niños de hoy. Barcelona: Edit. Ariel.

Moreno, A. y López de Maturana, S. (2015). Ambientes educativos escolares: una investigación sobre la propensión a aprender en jardines infantiles chilenos. Revista Estudios Pedagógicos, (en prensa).

Perrenoud, P. (1990). La construcción del éxito y del fracaso escolar. Madrid: Ediciones Morata.

Romano, V. (1998). La formación de la mentalidad sumisa. Madrid: Ediciones Endymion. 